\title{
REFLEXÕES SOBRE A CRISE NA DETERMINAÇÃO DOS DIREITOS FUNDAMENTAIS NOS PENSAMENTOS DE THOMAS HUMPHREY MARSHALL E KAREL VASAK
}

\section{REFLECTIONS ABOUT THE CRISIS ON DETERMINING THE FUNDAMENTAL RIGHTS IN THOMAS HUMPHREY MARSHALL'S AND KAREL VASAK'S THOUGHTS}

\author{
Norton Maldonado Dias \\ Faculdade de Direito de Sinop - Fasipe (Sinop, MT, Brasil)
}

Edinilson Donisete Machado

Centro Universitário Eurípides Soares da Rocha - Univem (Marília, SP, Brasil)

Recebimento: 7 mar. 2016

Aceitação: 2 dez. 2016

\begin{abstract}
Como citar este artigo / How to cite this article (informe a data atual de acesso / inform the current date of access):
DIAS, Norton Maldonado; MACHADO, Edinilson Donisete. Reflexões sobre a crise na determinação dos direitos fundamentais nos pensamentos de Thomas Humphrey Marshall e Karel Vasak. Revista da Faculdade de Direito UFPR, Curitiba, PR, Brasil, v. 62, n. 1, jan./abr. 2017, p. 183 - 208. ISSN 2236-7284. Disponível em: <http://revistas.ufpr.br/direito/article/view/45775>. Acesso $\quad$ em: $30 \quad$ abr. $2017 . \quad$ DOI:
\end{abstract} http://dx.doi.org/10.5380/rfdufpr.v62i1.45775.

\section{RESUMO}

O processo de determinação e surgimento dos direitos fundamentais pode ser vislumbrado por dois significativos pensamentos: um primeiro, proposto por Karel Vasak, adentra em uma crise quando se verifica o aspecto cronológico e histórico de proteções jurídicas que acabam por estar em descompasso com o processo de proteção verificável em tratados e convenções internacionais, e um segundo, que propõe o surgimento e a determinação de direitos fundamentais na perspectiva da cidadania, formulado por Thomas Humphrey Marshall e que acaba por ficar bastante adstrito ao contexto político do histórico britânico, inclusive ignorando o aspecto coletivo e difuso inerentes à noção de prerrogativas compreendidas como fundamentais na atualidade. $\mathrm{O}$ trabalho, pelo método dedutivo e bibliográfico, reconhece o surgimento e determinação desses direitos como decorrente de vários fatores, reduzindo a proteção e positivação jurídica a uma dentre as várias influências no processo de seu surgimento. E, também, propõe a solução por meio do realce ao aspecto principiológico de aplicação do postulado da ponderação, desconsiderando propostas que fragmentam esses direitos em diferentes fases de proteção, confrontando suas respectivas naturezas indivisíveis.

\section{PALAVRAS-CHAVE}

Direitos Fundamentais. Dimensões de Direitos. Cidadania.

\section{ABSTRACT}

The process of determination and emergence of the fundamental rights can be discerned from two significant thoughts: the first one is proposed by Karel Vasak, and turns into a crisis when the 
chronological and historical aspects of juridical protections end up not being in agreement with the process of verifiable protection in treaties and international conventions. The second thought, formulated by Thomas Humphrey Marshall, proposes the emergence and determination of the fundamental rights from a citizenship perspective, and becomes quite constricted with the political context of the British history, ignoring the collective and diffuse aspect of understanding prerogatives that are fundamental nowadays. The study, using a deductive and bibliographical method, recognizes the emergence and determination of these rights as resulting from several elements, reducing the juridical protection and affirmation to one among several influences in the process of its emergence. Also, it proposes a solution by highlighting the principle-related aspect of application of the pondering postulate, ignoring the proposals that divide these rights in different phases of protection, confronting their respective indivisible nature.

\section{KEYWORDS}

Fundamental rights. Rights dimensions. Citizenship.

\section{INTRODUÇÃO}

No estudo dos direitos fundamentais há, entre as várias vertentes que buscam explicar o histórico de seu surgimento e proteção, uma relevante e repercutida classificação que sistematiza o histórico de proteção dos direitos compreendidos como fundamentais em diferentes momentos de proteção. Conforme o termo originalmente proposto por Karel Vasak, trata-se das "gerações de direitos".

A proposta teórica original de Karel Vasak restringe-se a três fases de proteção no processo de determinação dos direitos compreendidos como fundamentais: um primeiro momento voltado para os direitos civis e políticos; posteriormente, a previsão de uma segunda fase de proteção, destinada a prever os direitos sociais e econômicos; e, por fim, o terceiro momento de proteção de direitos, voltado às prerrogativas ligadas à fraternidade, abrangendo os bens coletivos, desde recursos hídricos, o meio ambiente de um modo geral, ou ainda, patrimônio histórico ou os bens da humanidade e tantos outros atrelados ao valor fraternidade (encerrando o lema francês da Revolução de 1789: liberdade, igualdade e fraternidade).

O problema que o trabalho se propõe a enfrentar está atrelado ao reconhecimento de desvios na proposta de Karel Vasak, uma vez que a proposta cronológica de proteção de direitos verificável no constitucionalismo não acompanhou a ordem sequencial e cronológica de proteção no âmbito dos tratados e convenções internacionais, tendo em vista que inicia-se seu processo de proteção de direitos pelas prerrogativas atinentes ao trabalho (convenções da Organização Internacional do Trabalho OIT - de 1919) e não com os direitos civis e políticos, como é apresentada pela classificação teórica das dimensões de direitos. 
Ainda, o trabalho buscará transcrever os problemas da vertente de Thomas Humphrey Marshall na obra intitulada “Cidadania, classe social e status”, que também vislumbrou a ideia de determinação de direitos, porém de maneira diversa, ou seja, na perspectiva da acepção de cidadania, sendo pertinente o respectivo aprofundamento como um ideário também reconhecido e bastante repercutido cientificamente, principalmente na esfera sociológica.

Assim, a crise das propostas teóricas de determinação e surgimento dos direitos compreendidos como fundamentais serão analisadas em duas subdivisões bastante trabalhadas: uma tratando da crise na perspectiva de Karel Vasak e outra, diversa, concernente à visão de Thomas Humphrey Marshall, sendo desenvolvida e respondida sob a hipótese da solução técnica normativa baseada na Teoria dos Princípios, que deve se aproveitar do aspecto principiológico de direitos fundamentais como forma de invocar as técnicas de aplicação e ponderação de interesses nessa aplicação, contornando as falhas e desvios dos pensamentos desses autores.

Por fim, vale a análise finda, correspondente ao enriquecimento das ideias mediante conteúdos que fogem ao arcabouço positivista e pós-positivista, reportando os pensamentos críticos à dogmática jurídica, incluindo fatores sociológicos, históricos e políticos que influenciaram no processo de surgimento de direitos. Insere-se ainda a discussão de uma realização excludente de prerrogativas fundamentais que protegeram direitos que, embora teorizados como universais, destinaram-se a ser materializados somente para alguns, em detrimento dos demais.

\section{DA PROPOSTA TEÓRICA DOS DIREITOS FUNDAMENTAIS À LUZ DO PENSAMENTO DE KAREL VASAK}

No estudo dos direitos fundamentais, o pensamento que é mais reconhecido acerca das fases de surgimentos e determinação desses direitos, de modo a compreender o processo de proteção dessas prerrogativas, consiste nas aclamadas dimensões de direitos fundamentais.

A autoria do pensamento das dimensões de direitos, que originariamente foram denominadas de gerações, é atribuída ao jurista Karel Vasak, que, apesar de nascido na Tchecoslováquia, recebeu as influências da França, berço da Revolução de 1789. Foi neste país que o autor desenvolveu seus estudos e onde chegou a se naturalizar, revelando as primeiras ideias que culminaram no atrelamento das fases de determinação dos direitos fundamentais ao lema revolucionário francês do século XVIII: liberdade, igualdade e fraternidade.

Vale ressaltar que Roberto Gonzales Alvarez, professor da Faculdade de Direito na Universidad Nacional de San Antonio Abad del Cusco, reconheceu, no seu trabalho intitulado 
Aproximaciones a los Derechos Humanos de Cuarta Generación, que já havia ideias de relacionar as três expressões do lema revolucionário de 1789 (liberdade, igualdade e fraternidade) com o histórico constitucionalista de se prever essas prerrogativas, favorecendo assim o surgimento de tais pensamentos por volta de 1979.

Porém, o significativo registro de uma teoria que atrelou as fases de surgimento dos direitos fundamentais às três expressões do lema revolucionário francês de 1789 aponta à aula inaugural dos cursos promovidos pelo Instituto dos Direitos Humanos de Estrasburgo (BONAVIDES, 2006, p. 563). O curso datado de 1979, proferido pelo jurista Karel Vasak, trata desses pensamentos utilizando a expressão gerações, como forma de se referir às fases de determinação dos direitos fundamentais:

[...] a) primeira geração dos direitos seria a dos direitos civis e políticos, fundamentados na liberdade (liberté), que tiveram origem com as revoluções burguesas; b) a segunda geração, por sua vez, seria a dos direitos econômicos, sociais e culturais, baseados na igualdade (égalité), impulsionada pela Revolução Industrial e pelos problemas sociais por ela causados; c) por fim, a última geração seria a dos direitos de solidariedade, em especial o direito ao desenvolvimento, à paz e ao meio ambiente, coroando a tríade com a fraternidade (fraternité), que ganhou força após a Segunda Guerra Mundial, especialmente após a Declaração Universal dos Direitos Humanos, de 1948. (MARMELSTEIN, 2008, p. 42)

Nesse sentido é que as ideias de afirmação de direitos fundamentais, a partir de fases de sua proteção, surgem na já mencionada aula proferida por Karel Vasak, sobre a qual vale o aprofundamento, no intento de analisar o objeto da ministração, ainda não discutido, mas totalmente relacionado à oficialização deste pensamento tão reiterado na busca pelo momento em que tais direitos foram determinados.

A determinação de direitos fundamentais, a partir da perspectiva de proteções, em fases diversas, alinha-se ao lema revolucionário francês de 1789, pois a investigação levanta o dado de que o objeto da aula diz respeito justamente aos direitos do homem da terceira geração e aos direitos de solidariedade, bastando para esta conclusão verificar o próprio título da aula inaugural: Pour les droits de l'homme de la troisième génération: les droits de solidarieté ${ }^{1}$, bem como a relevância desta aula no intento de compreender a repercussão atualmente existente acerca deste pensamento (BARROS, [20--]).

A aula inaugural promovida pelo Instituto Internacional dos Direitos Humanos, em Estrasburgo, não era uma simples aula, pois o palestrante, Karel Vasak, era o Diretor da Divisão de Direitos do Homem e da Paz da Unesco - foi agendada para abrir os cursos de inauguração da própria instituição (BARROS, [20-]).

\footnotetext{
1 “Pelos direitos do homem da terceira geração: os direitos da solidariedade” (Tradução nossa).
} 
Porém, com o propósito de compreender o fator que mais influenciou a atual projeção deste pensamento, encontra-se a repercussão da obra A Era dos Direitos, de Norberto Bobbio, na qual se afirma categoricamente que o "desenvolvimento dos direitos do homem passou por três fases", explicando que “num primeiro momento, afirmaram-se os direitos de liberdade.” (BOBBIO, 2004, p. 32)

Quanto à nomenclatura das fases de proteção, vale ressaltar as corrigendas admitidas, pelos próprios constitucionalistas, justamente em razão do aspecto sucessório não condizente com o sentido cumulativo que deveria levar à intitulação das fases de proteção de direitos, algo que o próprio Ingo Sarlet assevera em sua doutrina:

[...] a teoria dimensional dos direitos fundamentais não aponta, tão-somente, para o caráter cumulativo do processo evolutivo e para a natureza complementar de todos os direitos fundamentais, mas afirma, para além disso, sua unidade e indivisibilidade no contexto do direito constitucional interno [...] (SARLET, 2008, p. 49-50).

Na vertente internacionalista, Cançado Trindade (1993, p. 30) faz significativas ponderações sobre a ideia de sucessória trazida pelo significado da nomenclatura que intitulou o pensamento na elaboração:

[...] a fantasia nefasta das chamadas "gerações de direitos”, histórica e juridicamente infundada, na medida em que alimentou uma visão fragmentada ou atomizada dos direitos humanos, já se encontra devidamente desmistificada. O fenômeno que hoje testemunhamos não é o de sucessão, mas antes, de uma expansão, cumulação e fortalecimento dos direitos humanos consagrados, consoante uma visão necessariamente integrada de todos os direitos humanos. As razões histórico-ideológicas da compartimentalização já há muito desapareceram. Hoje podemos ver com clareza que os avanços nas liberdades públicas em tantos países nos últimos anos devem necessariamente fazer-se acompanhar não de retrocesso - como vem ocorrendo em numerosos países - mas de avanços paralelos no domínio econômico-social.

Na linha de uma crescente vertente doutrinária formada, principalmente, por autores internacionalistas da literatura jurídica, releva-se uma significativa crítica acerca do desenvolvimento e da construção do ideário das dimensões de proteção dos direitos fundamentais:

A classificação tradicional, porém, tem sido objeto de recentes críticas, as quais apontam para a não correspondência entre as gerações e o processo histórico de nascimento e desenvolvimento dos direitos humanos. Mais além, verifica-se que a difundida noção tem acarretado confusões conceituais acerca de suas características distintivas dos direitos humanos (WEIS, 1999, p. 40).

Ocorre que o pensamento que defende a ordem de previsão dos direitos fundamentais na linha das dimensões de direitos não se verifica quando internacionalistas se propõem a conferir o histórico de proteção jurídica desses direitos em documentos e textos de natureza diversa da dos textos 
de essência constitucional. Nesse sentido, no caso, observa-se a ordem do histórico de proteção ocorrida em textos provenientes de Tratados e Convenções Internacionais.

Na esfera dos Tratados e Convenções Internacionais, surpreendentemente, os primeiros direitos relativos à pessoa humana não foram os civis e políticos, como propõe o ideário trazido por Karel Vasak, mas os direitos relativos ao trabalho, com a Convenção da OIT datada de 1919:

O autor Antônio A. Cançado Trindade destaca o descompasso entre o direito interno dos países e o direito internacional público. Se no primeiro o reconhecimento dos direitos sociais pelas constituições foi, no geral, posterior ao dos direitos civis e políticos, no plano internacional o surgimento da Organização Internacional do Trabalho, em 1919, propiciou a elaboração de diversas convenções regulamentando os direitos sociais dos trabalhadores, antes mesmo da internacionalização dos direitos civis e políticos (WEIS, 1999, p. 40-41).

Os direitos civis e políticos foram protegidos, no âmbito internacional, segundo a vertente de autoria de Karel Vasak, somente em 1966, com o intitulado Pacto Internacional dos Direitos Civis e Políticos. Ocorre, porém, que deve ser destacado que uma crescente doutrina internacionalista consiste no reconhecimento da ruptura do histórico de proteção até então defendida de modo quase que pacífico pelos constitucionalistas; porém, de fato, a ordem cronológica proposta por Karel Vasak é quebrada quando vislumbrada na perspectiva internacionalista. As principais obras em que se pode verificar essa vertente crítica são "Direitos humanos contemporâneos” (WEIS, 2010); “Classificação dos direitos fundamentais: do sistema geracional ao sistema unitário - uma proposta de compreensão” (SCHÄFER, 2013) e “Curso de direito internacional público” (MAZZUOLLI, 2013), na qual se afirma claramente:

[...] a consagração nas Constituições dos direitos sociais foi, em geral, posterior à dos direitos civis e políticos, ao passo que no plano internacional o surgimento da Organização Internacional do Trabalho, em 1919, propiciou a elaboração de diversas convenções regulamentando os direitos sociais dos trabalhadores, antes mesmo da internacionalização dos direitos civis e políticos no plano externo (MAZZUOLI, 2013, p. 858).

Portanto, a primeira vez em que se positivaram direitos atinentes à pessoa humana, à luz de normas de direito internacional, não foi quando do advento dos direitos civis e políticos no século XIX, mas no início do século XX, com direitos essencialmente sociais, e por isso o precedente histórico explica o processo de internacionalização dos direitos humanos. Assinala-se, assim, a Liga das Nações e a Organização Internacional do Trabalho, por meio das quais foi possível, pela primeira vez, "redefinir o status do indivíduo no cenário internacional, para que se tornasse verdadeiro sujeito de direito internacional” (PIOVESAN, 2003, p. 125).

Vale notar que o fenômeno de criação das dimensões de direitos não é um fenômeno estritamente brasileiro, sua crítica compreende os autores estrangeiros, dentre os quais destaca-se 
Fernando Falcon y Tella, em sua obra intitulada Challenges for human rights (FALCON Y TELLA, 2007).

O próprio Cançado Trindade ressalta o pensamento como infundado juridicamente, referenciando a expansão dos direitos fundamentais e a devida integralidade dos direitos humanos, de modo que a compartimentalização já há muito tempo desapareceu:

[...] a fantasia nefasta das chamadas "gerações de direitos", histórica e juridicamente infundada, na medida em que alimentou uma visão fragmentada ou atomizada dos direitos humanos, já se encontra devidamente desmistificada. O fenômeno que hoje testemunhamos não é o de sucessão, mas antes, de uma expansão, cumulação e fortalecimento dos direitos humanos consagrados, consoante uma visão necessariamente integrada de todos os direitos humanos. As razões histórico-ideológicas da compartimentalização já há muito desapareceram. Hoje podemos ver com clareza que os avanços nas liberdades públicas em tantos países nos últimos anos devem necessariamente fazer-se acompanhar não de retrocesso - como vem ocorrendo em numerosos países - mas de avanços paralelos no domínio econômico-social. (TRINDADE, 1997, p. 390)

Observando a ruptura no histórico de proteção, pode-se concluir que a classificação de Karel Vasak foi retirada de verificações estritamente voltadas aos conteúdos que estavam sendo positivados, ou seja, direitos civis e políticos, sociais e econômicos e assim por diante. Assim, o critério sobre o qual foi construído o ideário classificatório no histórico de previsão está baseado apenas nos critérios dos conteúdos que foram sendo positivados.

Tratou-se, portanto, de um critério bastante vulnerável, uma vez que a conferência doutrinária do histórico de previsão de conteúdos (direitos civis e políticos, sociais e econômicos e assim por diante) seria reduzida a uma variável quando a conferência não se verificasse à luz de outras perspectivas não estudadas. Ou seja, tratou-se de um pensamento que vislumbrou somente uma perspectiva e arriscando toda construção teórica e classificatória assentada não em uma constante, mas na variável de um critério essencialmente formal e positivista focada nos objetos que estavam sendo positivados.

Ocorre que Cançado Trindade questionou pessoalmente Karel Vasak acerca dos métodos utilizados por ele na V Conferência Nacional de Direitos Humanos, realizada em Brasília em 25 de maio de 2000:

Essa teoria é fragmentadora, atomista e toma os direitos de maneira absolutamente dividida, o que não corresponde à realidade. Eu conversei com Karel Vasak e perguntei: "Por que você formulou essa tese em 1979?”. Ele respondeu: “Ah, eu não tinha tempo de preparar uma exposição, então me ocorreu fazer alguma reflexão, e eu me lembrei da bandeira francesa” ele nasceu na velha Tchecoslováquia. Ele mesmo não levou essa tese muito a sério, mas, como tudo que é palavra “chavão”, pegou (HONESKO, 2008, p. 189). 
Portanto, conclui-se que a perspectiva cega de considerar apenas a análise de textos de natureza constitucional não projetou conferências críticas de contextualizações jurídicas de natureza diversa daquela considerada na elaboração genuína. Deixando, assim, bastante vulnerável o pensamento que foi construído somente considerando o fator do histórico de positivação de direitos, ignorando que a proteção e positivação de prerrogativas não é a única fonte que deve ser considerada. Ou seja, os direitos compreendidos como fundamentais surgem e são determinados a partir de vários fatores, dentre os quais, os de natureza política, antropológica, histórica, sociológica, psicológica, tecnológica; em suma, de tantos outros, reduzindo a positivação jurídica e o respectivo histórico de proteção a apenas uma das influências a ser considerada.

\section{DA PROPOSTA TEÓRICA DOS DIREITOS FUNDAMENTAIS À LUZ DO PENSAMENTO DE THOMAS HUMPHREY MARSHALL}

Aproveitando o propósito de tratar de crises na proposta classificatória acerca dos direitos fundamentais, vale invocar o tradicional discurso de Thomas Humphrey Marshall a respeito da cidadania como uma forma de demonstrar pensamentos diversos das ideias de Karel Vasak, que de nenhum modo foi o único e reconhecido pensamento teórico que classificou e estudou a determinação dos direitos fundamentais.

Pode-se dizer que transcrever sobre uma crise ou sobre situações críticas acerca de uma determinada proposta teórica não está restrito a apontar os defeitos e vícios internos de um determinado pensamento, podendo inserir a existência de outras propostas, tão bem aceitas e até com significativo reconhecimento por parte da doutrina especializada. Assim, nesse sentido, vale tratar de outra classificação diversa, também bastante reconhecida, consagrada e, também, muito bem aceita no âmbito dos direitos fundamentais.

No trabalho intitulado Cidadania, classe social e status, escrito em 1949 por Thomas Humphrey Marshall, o fenômeno da cidadania foi analisado como uma composição inicialmente formada pelos direitos civis; depois, pelos direitos políticos, e, por fim, pelos direitos sociais, compondo, assim, um pensamento com significativas similaridades em relação às denominadas dimensões de direitos:

\footnotetext{
Quando se separaram, os três elementos da cidadania romperam, por assim, dizer, toda relação. Tão completo foi o divórcio que, sem violentar demasiadamente a precisão histórica, podemos designar o período formativo de cada um a um século distinto - os direitos civis, no século XVIII; os políticos, no século XIX; e os sociais, no século XX. Como é natural, estes períodos deverão ser tratados com uma razoável elasticidade, e há certo solapamento evidente, sobretudo entre os dois últimos. (MARSHALL, 1967, p. 65)
} 
Assim, para Marshall, a cidadania parte de três elementos particulares: civil, político e social, sendo o Estado o eixo central no processo de aquisição da cidadania, pressupondo uma relação de dependência com o Estado nessa construção.

Os direitos civis teriam surgido no século XVIII, e estão relacionados a prerrogativas como a liberdade individual, liberdade de imprensa, pensamento, liberdade de fé e crença religiosa, acesso à justiça, propriedade privada, direito de ir e vir, sendo direitos indispensáveis para a economia de mercado, coexistindo, portanto, com o sistema capitalista (MARSHALL, 1967, p. 85).

Para Marshall o século XVIII foi, de fato, marcado como um tempo de determinação dos direitos civis:

Compreende lealdade de homens livres, imbuídos de direitos e protegidos por uma lei
comum. Seu desenvolvimento é estimulado tanto pela luta para adquirir tais direitos quanto
pelo gozo dos mesmos, uma vez adquiridos. Percebe-se isto claramente no século XVIII, o
qual assistiu ao nascimento não apenas dos direitos civis, mas também da consciência
nacional de nossos dias. (MARSHALL, 1967, p. 84)

Assim, a cidadania, compreendida como civil, abarca os direitos necessários ao exercício da liberdade individual, como a liberdade de ir e vir, liberdade para firmar contratos, possuir propriedades e outros, sendo garantidos pela legalidade.

Já os direitos políticos, como aqueles concebidos no século XIX, são considerados produtos secundários dos direitos civis, expressando o direito de participação no exercício do poder político. Tal poder é expresso por meio da possibilidade de ser membro de organismo com autoridade política ou pelo direito de voto, não existindo, de fato, uma igualdade política, justamente por existir preconceito de classe, expresso por meio da intimidação das classes inferiores pelas superiores, impedindo o livre exercício do direito de voto:

[...] os direitos políticos da cidadania, ao contrário dos direitos civis, estavam repletos de ameaça potencial ao sistema capitalista, embora aqueles que estavam estendendo, de modo cauteloso, tais direitos às classes menos favorecidas provavelmente não tivessem plena consciência da magnitude de tal ameaça (MARSHALL, 1967, p. 85).

Os direitos políticos, desse modo, correspondem ao direito de participar do poder político, tanto diretamente, quanto por meio do voto, fazendo parte das instituições representativas dos governos local e nacional.

Há, por fim, os direitos sociais que surgiram no século XX, ou seja, aqueles aptos a conferir um mínimo de condição econômica, acesso aos serviços educacionais e sociais, destacando que os direitos sociais mínimos foram desligados do status social da cidadania, de modo que, no exemplo do beneficiário da aclamada Poor Law, a qual corresponde ao auxílio financeiro garantido às famílias 
menos favorecidas, teria sua condição de cidadão usurpada (MARSHALL, 1967, p. 72). Nesse sentido, como forma de reafirmação da defesa do restabelecimento dos direitos sociais do século XX. Segundo Marshall, o ponto crucial para esse restabelecimento foi o desenvolvimento da educação primária pública obrigatória:

Tornou-se cada vez mais notório, com o passar do século XIX, que a democracia política necessitava de um eleitorado educado e que a produção científica se ressentia de técnicos e trabalhadores qualificados. O dever de autoaperfeiçoamento e de autocivilização é, portanto, um dever social e não somente individual, porque o bom funcionamento de uma sociedade depende da educação de seus membros. E uma comunidade que exige o cumprimento dessa obrigação começou a ter consciência de que sua cultura é uma unidade orgânica e sua civilização uma herança nacional. Depreende-se disto que o desenvolvimento da educação primária pública durante o século XIX constituiu o primeiro passo decisivo em prol do restabelecimento dos direitos sociais da cidadania no século XX. (MARSHALL, 1967, p. 74)

A cidadania compreendida como social, por sua vez, responde à necessidade básica, assegurando direito a um bem-estar econômico mínimo, relacionado primeiramente, entre outros, com o direito ao salário, à saúde, à educação, à habitação, à alimentação, podendo-se observar outra diferença no contexto brasileiro, considerando que Marshall defende a educação primária obrigatória como fundamental para o desenvolvimento da cidadania.

Vale ressaltar que Marshall observa como um mínimo aquilo que os direitos sociais compreendiam, e algo que não fazia parte do conceito de cidadania, sendo preciso que tais direitos fossem incorporados ao status de cidadania:

O período com o qual me ocupei até o momento se caracterizou pelo fato de o desenvolvimento da cidadania, conquanto substancial e marcante, ter exercido pouca influência direta sobre a desigualdade social. Os direitos civis deram poderes legais cujo uso foi drasticamente prejudicado por preconceito de classe e falta de oportunidade econômica. Os direitos políticos deram poder potencial cujo exercício exigia experiência, organização e uma mudança de ideias quanto às funções próprias de Governo. Foi necessário bastante tempo para que estes se desenvolvessem. Os direitos sociais compreendiam um mínimo e não faziam parte do conceito de cidadania. A finalidade comum das tentativas voluntárias e legais era diminuir o ônus da pobreza sem alterar o padrão de desigualdade do qual a pobreza era, obviamente, a consequência mais desagradável. Iniciou-se um novo período no final do século XIX [...]. Essas aspirações tornaram-se realidade, ao menos em parte, pela incorporação dos direitos sociais ao status da cidadania. (MARSHALL, 1967, p. 88)

Mencione-se, inclusive, o trecho em que Marshall explica como o desenvolvimento inglês e o progresso foi resultando em maior distribuição da renda, assentando um processo evolutivo de condições sociais, revelando, assim, a necessidade do desenvolvimento desta dimensão social para fins de alcançar a cidadania plena:

Assistiu ao primeiro grande avanço no campo dos direitos sociais, e isto acarretou mudanças significativas no princípio igualitário como expresso da cidadania. Mas havia outras forças operando também. Um aumento de rendas nominais desigualmente distribuídas pelas classes 
sociais modificou a distância entre trabalhadores especializados e não especializados e entre trabalhadores não-manuais, ao passo que o aumento contínuo das pequenas poupanças obscureceu a distinções de classe entre o capitalista e o proletário sem bens [...] Finalmente, a produção em massa para o mercado interno e o crescente interesse da indústria pelas necessidades e gostos de massa capacitaram os menos favorecidos a gozar de uma civilização material que diferia de modo menos acentuado em qualidade daquela dos abastados do que em qualquer outra época. Os componentes de uma vida civilizada e culta, originariamente o monopólio de poucos, foram, aos poucos, postos ao alcance de muitos. A diminuição da desigualdade fortaleceu a luta pela sua abolição [...]. (MARSHALL, 1967, p. 88)

Desse modo, o desenvolvimento da cidadania em Marshall depende do desenvolvimento dos direitos civis, seguidos dos direitos políticos e dos direitos sociais, nos séculos XVIII, XIX e XX, respectivamente, introduzindo, assim, o conceito de direitos sociais e a ideia de plenitude de cidadania somente quando dotada dos três tipos de direito, sendo uma condição ligada à classe social.

Marshall vislumbra a determinação dos direitos dentro da concepção de cidadania que não deixa de celebrar o indivíduo enquanto unidade política desvinculado das instituições gremiais e corporativas, cujo início ocorreu nas revoluções inglesas do século XVII, Revolução Francesa de 1789 e Bill of Rights, possuindo aspirações nos direitos naturais, devendo ser reconhecidos e protegidos pelo poder.

A ideia de cidadania inserida no contexto da modernidade e da estruturação do Estado-nação passa a ocupar um campo mais amplo, no qual esta ideia é definida como a posse de direitos civis, políticos e sociais, sendo uma noção ainda em um processo de construção que, segundo Marshall, desenvolve-se desde o século XVII:

[...] a cidadania tem sido uma instituição em desenvolvimento na Inglaterra pelo menos desde a segunda metade do século XVII, então é claro que seu crescimento coincide com o desenvolvimento do capitalismo que é o sistema não de igualdade, mas de desigualdade. (MARSHALL, 1967, p. 76)

Não se pode perder de vista que a perspectiva de Marshall acaba ficando muito restrita ao contexto britânico, marcado pelo desenvolvimento da industrialização concomitantemente à democracia, de modo que, invocado o exemplo dos Estados Unidos, a mobilização popular ocorreu antes da industrialização.

Por isso, há significativas ponderações ao pensamento de Marshall atinente à sociedade britânica, sendo um pensamento focado nos problemas econômicos, políticos e sociais restritos ao contexto britânico, apontado como uma perspectiva não tão ampla, universal e abrangente como tenta a proposta de Karel Vasak, que possui sérias limitações quando relacionada aos problemas e às peculiaridades de outros países (MOURA, 2009). 
Observa-se, por exemplo, a trajetória brasileira, com significativas ponderações acerca das diferenças, em detrimento da evolução inglesa, no tocante ao pensamento de Marshall:

Sob tal perspectiva, existiam duas importantes diferenças entre a trajetória inglesa e a brasileira: "a primeira refere-se à maior ênfase em um dos direitos, o social, em relação aos outros. A segunda refere-se à alteração na sequência em que os direitos foram adquiridos: entre nós o social precedeu os outros”. (CARVALHO, 2001, p. 11)

Nesse sentido, como argumenta Moura (2009, p. 23, grifo do autor),

[...] podemos afirmar que uma das maiores discrepâncias desses sistemas reside no fato de que o tripé que compõe a cidadania - direitos políticos, civis e sociais - foi por aquele povo conquistado e, para nós, doado, segundo os interesses particulares dos governantes de plantão.

Outra crítica bastante significativa é correspondente ao pensamento de Marshall, que assevera que os direitos sociais se afastaram da ideia de status da cidadania, considerando-se a política do Poor Law e das necessidades do capitalismo (MOURA, 2009).

José Murilo de Carvalho, em um trabalho intitulado Cidadania no Brasil: o longo caminho, dispõe uma lógica inversa da proposta de Marshall, que, inclusive, serve para denotar ainda mais a fórmula não universal e adstrita ao contexto britânico do pensamento de Marshall, asseverando que, primeiro,

[...] vieram os direitos sociais, implantados no período da supressão dos direitos políticos e de redução dos direitos civis por um ditador que se tornou popular (Getúlio Vargas). Depois vieram os direitos políticos [...] [A] expansão dos direitos do voto deu-se em outro período ditatorial, em que os órgãos de repressão política foram transformados em peça decorativa do regime [militar] [...] A pirâmide dos direitos no Brasil foi colocada de cabeça para baixo. (CARVALHO, 2001, p. 219-229)

Cidadania, para Marshall, consiste, portanto, no pertencimento pleno a uma comunidade, de modo que a expressão pertencimento implica a participação dos indivíduos na determinação das condições de sua própria associação, sendo um status que garante aos indivíduos iguais direitos e deveres, liberdades e restrições, poderes e responsabilidades (EDELMAN, 1973, p. 70-84).

A principal ponderação ao pensamento de Marshall está em confiar, sobremaneira, nas forças do progresso, no desenvolvimento da sociedade, apesar de reconhecer que o sistema econômico funciona produzindo desigualdades, de modo a gerar pensamentos como de Anthony Giddens, que, ao refletir sobre o tema, entende que as dimensões de direitos civis, políticos e sociais foram conseguidas à custa de ações, organizadas ou não, de expressivos segmentos sociais (GIDDENS, 1987, p. 78-103). 
Logicamente que não se pode perder de vista a relevância da obra de Marshall, uma vez que ele foi o primeiro que elaborou a distinção sociológica entre cidadania civil, política e social e, ao mesmo tempo, defendeu a interdependência entre esses três tipos de cidadania (MARSHALL, 1967, p. 78-79), com significativas proximidades com a característica da inter-relacionariedade dos direitos fundamentais que confronta diretamente a proposta teórica de Karel Vasak.

Confrontando o pensamento de Marshall proposto para o contexto britânico e inserido na acepção de cidadania enquanto direito de aquisição de direitos, desenvolvido para pensar os direitos e obrigações inerentes à condição de cidadão, pode-se fazer um paralelo com as ideias de Karel Vasak: os direitos civis e políticos que Marshall concluiu como determinados, nos séculos XVIII e XIX, seriam, respectivamente, os direitos compreendidos por Vasak como de primeira dimensão e, por fim, os direitos sociais concluídos por Marshall no século XX seriam os direitos compreendidos por Karel Vasak como de segunda dimensão.

Portanto, o pensamento, em que pese marcado com análise séria e construção significativa, possui restrições quanto às peculiaridades britânicas inviabilizadoras da universalização e significativas críticas. Assim, deve-se ressaltar a ausência expressa da menção dos aclamados direitos de quarta e quinta dimensão (direitos atinentes à solidariedade que transcende a esfera do individual), orientando para que o trabalho prossiga na proposta de Karel Vasak, a qual abarca não só as prerrogativas da tutela coletiva, mas a universalização de outros países.

\section{DA SOLUÇÃO AOS PROBLEMAS NAS PROPOSTAS DE SURGIMENTOS E DETERMINAÇÃO DOS DIREITOS FUNDAMENTAIS PELA TEORIA DOS PRINCÍPIOS}

Fica bastante evidente que o fator crítico do pensamento de Karel Vasak assentou sua construção teórica no histórico de formalização de direitos, e o critério adotado não está apto para ser o único no surgimento de uma prerrogativa, uma vez que a formalização e a positivação de direitos é variável política e geograficamente e que é salutar que características de direitos retirados da natureza humana não possam ter o mesmo aspecto oscilante, de modo que o próprio Bobbio dá exemplo de direitos que surgiram em razão do desenvolvimento tecnológico e não de mera formalização positivista de uma estrutura política:

[...] as exigências que se concretizam na demanda de uma intervenção pública e de uma prestação de serviços sociais por parte do Estado só podem ser satisfeitas num determinado nível de desenvolvimento econômico e tecnológico; e que, com relação à própria teoria, são precisamente certas transformações sociais e certas inovações técnicas que fazem surgir novas exigências, imprevisíveis e inexequíveis antes que essas transformações e inovações 
tivessem ocorrido. Isso nos traz uma ulterior conformação da socialidade, ou da nãonaturalidade, desses direitos. (BOBBIO, 1992, p. 76)

Já no pensamento de Marshall, em que pese significativo reconhecimento, vale ressaltar que o contexto histórico se atrela ao estudo intrinsecamente ligado à Revolução Industrial britânica, que pode ser assimilado com as revoluções industriais de países escandinavos, mas não como uma fórmula genérica de compreensão dos direitos fundamentais universais.

A perspectiva principiológica roga pela integralidade de princípios como a dignidade da pessoa humana que não podem ser vislumbrados a depender tão somente das políticas públicas a serem consideradas como única e exclusiva fonte de determinação, sem desconsiderar a significativa importância em sua respectiva implementação.

Não se pode perder de vista que o elemento essencial à prova da fundamentalidade desses direitos deve residir não somente no catálogo dos direitos fundamentais (enfatizando sua essência não exaustiva), mas deve ser retirado como decorrente do princípio da dignidade da pessoa humana:

Assim, a cláusula constitucional que permite a abertura a novos direitos fundamentais deve ser interpretada como tendo função maximizadora da estrutura protetiva fundamental. A busca de direitos não expressamente elencados no Catálogo dos Direitos Fundamentais (sejam eles novos ou não, escritos ou não) deve ser criteriosa, objetivando-se alcançar padrão mínimo de reconhecimento, para que essa cláusula se transforme em inimiga dos direitos fundamentais. O elemento essencial à prova da fundamentalidade desses direitos deve residir, em última instância, no princípio constitucional da dignidade da pessoa humana. (SCHÄFER, 2013, p. 37)

Os direitos fundamentais se encontram ligados, de modo que sua compreensão fragmentada, que ignora significativa indivisibilidade, desconsidera a interligação entre estruturas variáveis de todos os direitos fundamentais. Assim, reconhece-se que, cada vez mais, a eficácia concreta de certa posição jurídica constitucional se atrela às condutas, uma vez que não dá para separar o direito à liberdade (essencialmente negativa) e a segurança pública (essencialmente prestacional):

\begin{abstract}
A compreensão fragmentada dos direitos fundamentais (direitos negativos, de um lado, direitos positivos, de outro), sem a previsão de um regime jurídico geral, não permitiu que se constasse a interligação entre estruturas varáveis de todos os direitos fundamentais, nas quais cada vez mais à eficácia concreta de certa posição jurídica constitucional, independentemente de seu núcleo essencial, é dependente de pluralidade incindível de condutas comissivas e omissivas, as quais têm por destinatários tanto o Estado como o particular. Assim, não se questiona que o direito à liberdade (típico direito negativo) encontra-se intimamente ligado com o direito à segurança pública (direito prestacional); que o direito à liberdade de expressão é dependente do direito à educação; [...]. (SCHÄFER, 2013, p. 74)
\end{abstract}

A solução, assim, começa a ser construída no sentido de se afirmar uma proteção principiológica dos direitos fundamentais, superando os critérios classificatórios e diferenciatórios 
entre os direitos, uma vez que todos têm como objetivo essencial a proteção do princípio constitucional da dignidade da pessoa humana:

A compreensão principiológica dos direitos fundamentais demonstra ser a postura teórica em favor dos direitos fundamentais, no momento em que permite a visualização sistêmica e integral de todos os direitos fundamentais, superando critérios diferenciatórios entre os direitos que, ao final, têm todos como objetivo essencial a proteção da dignidade da pessoa humana, traduzindo comandos de potencialização no que se referem à proteção concreta dos respetivos núcleos essenciais. Nesse sistema, as normas jurídicas são subdivididas em princípios e regras. (SCHÄFER, 2013, p. 75)

Por isso a importância da proteção desses direitos, observando a compreensão principiológica e seus respectivos postulados em uma teoria constitucional de princípios e regras, devendo sofrer algumas adaptações à complexidade crescente da sociedade moderna:

O entendimento principiológico implica a compreensão dos direitos fundamentais em sua totalidade, vale dizer, como conjunto interligado de proposições constitucionais, as quais se condicionam mutuamente, gerando interdependências incompatíveis com a visão fragmentada do fenômeno. A Corte Constitucional italiana, na conhecida Sentenza Baldassare, reafirmou a importância dessa concepção principiológica na Constituição moderna, consignando que os princípios constitucionais têm validade vinculante superior relativamente a outras normas constitucionais. (SCHÄFER, 2013, p. 77)

Nesse sentido surge a ideia de que a solução de eventuais conflitos constitucionais, nomeadamente quanto a direitos constitucionais, deve ser buscada na proteção de formas pautadas em novos postulados de aplicabilidade:

[...] a solução de eventuais conflitos entre direitos constitucionais deve ser buscada cada vez mais na conciliação (ponderação) dos diversos valores litigiosos, numa visão de inclusão dos direitos ao sistema constitucional, substituindo-se a solução do "tudo ou nada", a qual implica absolutização e exclusão de direitos, pela técnica da ponderação no caso concreto. Mostrando-se adequada a solução do conflito entre regras jurídicas infraconstitucionais no campo da validade, a mesma sistemática relevou-se totalmente insuficiente ante as diferentes e complexas funções desempenhadas pela Constituição. (SCHÄFER, 2013, p. 77)

O Supremo Tribunal Federal tem aderido a esta solução principiológica, que tenta vislumbrar um sistema unitário em vez do sistema geracional, entrevendo sua aplicabilidade imediata observando a indivisibilidade:

A incindibilidade dos direitos fundamentais e a inexistência de diferenças estruturais entre os variados tipos de direito determinam a superação dos modelos teóricos embasados na separação estanque entre as esferas dos direitos sociais (positivos e prestacionais) e dos direitos de liberdade (negativos), afirmando-se a aplicabilidade imediata de todas as normas constitucionais, a partir da unidade de sentido dos direitos fundamentais. A diferença entre direitos negativos e direitos positivos é meramente de grau, uma vez que em ambos há expectativas negativas e positivas. Nesse contexto, os direitos políticos fundamentais apresentam uma estrutura jurídica complexa, pois exteriorizam características negativas (primeira geração) e, ao mesmo tempo, positivas (segunda e terceira geração). São preponderantemente direitos fundamentais individuais, pois garantem esferas de não 
interferência do Estado no âmbito das autonomias decisórias individuais, mas são exercitáveis mediante a ação garantidora do Estado, o qual deve organizar procedimentos que tem por objetivos instrumentalizar a concreção do exercício dos direitos, como é o caso, por exemplo, das eleições periódicas (BRASIL, 2011, p. 19).

Em que pese a jurisprudência, a compreensão unitária dos direitos fundamentais, em substituição à compreensão geracional, fornece postulados que facilitam contornos e precisão na tese por uma nova acepção (perspectiva unitária):

Dessa forma, a compreensão unitária dos direitos fundamentais embasa-se nos seguintes
postulados: Caráter incindível dos direitos fundamentais, decorrente da unidade de sentido
constitucional; Inexistência de diferenças estruturais entre os distintos tipos de direitos
fundamentais, dada a presença das diferentes expectativas (positivas e negativas), em maior
ou menor grau, em todos os direitos fundamentais; Interligação sistêmica e dialética entre
todas as espécies de direitos fundamentais, implicando comprometimento recíproco dos
direitos no que se refere à efetivação; Caráter principiológico de todos os direitos
fundamentais, implicando entende-los como mandados de otimização, sendo que a medida
exata do devido, em concreto, vai depender das possibilidades reais e jurídicas. Com isso, a
chamada "reserva do possível” é elemento que se integra externamente (plano da eficácia) a
todos os direitos fundamentais, independentemente de suas características intrínsecas, uma
vez não compor a estrutura formadora do direito fundamental; Inadequação de teorias
classificatórias que tenham por embasamento teórico a compartimentalização estanque dos
direitos fundamentais. (SCHÄFER, 2013, p. 81)

Assim, a perspectiva unitária afasta a acepção geracional, considerando o aspecto incindível dos direitos fundamentais, decorrentes da unidade constitucional; não reconhece distinções entre tipos diversos de direitos fundamentais, reconhece a interligação sistêmica entre todas as espécies de direitos fundamentais e, um dado de significativa relevância, reconhece o caráter principiológico dos direitos fundamentais.

No concernente ao aspecto principiológico dos direitos fundamentais, a vertente defensora busca responder à perspectiva subjetiva e da efetividade, que coloca as gerações e dimensões de direitos também em crise, conforme já discutido.

Essa proposta de resolução, pelo viés de um sistema unitário que considere a aplicabilidade imediata e observe o aspecto da indivisibilidade, pode ser percebida pelo mencionado julgado do Supremo Tribunal Federal. Ou seja, além de reconhecer as tão reafirmadas razões que levam as gerações às crises que assolaram o pensamento, também visitam valores e prerrogativas, entre os quais, anterioridade eleitoral, devido processo legal, igualdade e função contramajoritária da ideia de jurisdição constitucional, sem que possa haver diferenciações e categorizações acerca de conteúdos na essência indivisíveis e inter-relacionados:

Em outra oportunidade, quando do julgamento da constitucionalidade da lei da ficha limpa (Lei Complementar n. 135/2010) o Supremo Tribunal Federal uma vez teve oportunidade de visitar a temática referente à importância dos direitos fundamentais em nosso sistema 
constitucional (princípio da anterioridade eleitoral, devido processo legal, princípio da igualdade, função contramajoritária da jurisdição constitucional etc.), ficando assentada a necessidade de uma nova compreensão estruturante dos direitos fundamentais. (SCHÄFER, 2013, p. 82)

Portanto, o sistema não deveria ser o geracional pautado em considerar a perspectiva unicamente histórica de formalização positivista, como único modo de surgimento e conformação de prerrogativas, pois tal formalização histórica é um fator demasiadamente oscilante e os direitos fundamentais não possuem esses aspectos instáveis.

Vale lembrar que, entre as características desses direitos, há o aspecto indivisível que não se encaixa em uma proposta fragmentária que tenta generalizar o surgimento de direitos em diferentes fases autônomas dentro do histórico de formalização como o único para que direitos fossem admitidos. Esse momento de formalização de prerrogativas não pode ser único, exclusivo e absoluto fator neste processo, haja vista a inserção de uma série de influências a ser considerada nas mais diversas ordens, entre as quais, geopolíticas, sociológicas, antropológicas e até psicológicas, que, de fato, contribuem para o respectivo reconhecimento, surgimento e determinação de direitos compreendidos como fundamentais.

\section{RESIGNIFICANDO O PROCESSO DE AFIRMAÇÃO DOS DIREITOS FUNDAMENTAIS APÓS A CRISE DO CRITÉRIO JUSPOSITIVISTA}

As propostas fragmentárias, principalmente, de Karel Vasak, acabam sendo marcadas por significativas inconsistências, não compreendendo os diferentes históricos de proteções de prerrogativas que oscilam entre diferentes nações e processos históricos diversos, bem como outras vertentes que partem de positivações de naturezas diversas, como no âmbito dos tratados e convenções internacionais, que inicialmente protegiam não direitos civis e políticos, mas sim direitos sociais, com o advento da Convenção da Organização Internacional do trabalho (OIT) de 1919.

Trata-se, assim, de significativos desvios no critério de compreensão do surgimento de direitos fundamentais como único e exclusivo fator de verificação do surgimento de direitos. Para tal, basta verificar que, no processo de surgimento e determinação de prerrogativas, não há apenas a averiguação da positivação e formalização de certas prerrogativas, mas uma série de verificações concomitantes (sociológicas, históricas, antropológicas, tecnológicas e outras influências).

O próprio Thomas Humphrey Marshall, em que pese tenha uma proposta fragmentária que subdivide direitos, por natureza, incindíveis em fases históricas, rechaça o relacionamento e a 
influência da economia com esses direitos, reafirmando, justamente, fatores externos ao âmbito normativo.

Fica claro que as influências dentro do processo de surgimento de prerrogativas transcendem o âmbito juspositivista, podendo-se mencionar o desenvolvimento de fatores de naturezas diversas ao positivismo ético ou pós-positivismo que, embora objetos de discussão atual e moderna, demonstram que a afirmação de prerrogativas não deve decorrer somente de fatores normativos. Ou seja, deve-se proceder à verificação de necessidades de naturezas diversas, tais como sociológica, antropológica, histórica, política e de outras compreensões que transcendem a mera técnica normativa no processo de formação desses direitos.

Há, ainda, a suspeição da existência de medidas jurídicas e formas legais como fatores absolutos, inclusive em processos de afirmação de direitos: “[...] as medidas excepcionais encontramse na situação paradoxal de medidas jurídicas que não podem ser compreendidas no plano do direito e o estado de exceção apresenta-se como a forma legal daquilo que não pode ter forma legal.” (AGAMBEN, 2003, p. 11-12)

No trabalho intitulado Crítica da legalidade e do direito brasileiro, Mascaro (2008) eleva a discussão do direito a uma visão mais crítica e radical, enfatizando duas importantes questões. A primeira, baseada no conceito de legalidade, e a outra, pautada na realidade jurídica brasileira, enfatizando o aspecto crítico jusfilosófico na discussão neoliberal da atualidade.

No contexto da verificação do processo de surgimento de direitos, há de ser preservada a forma jurídica como um constituinte da sociabilidade capitalista, também como a política estatal, reconhecendo nesse processo as contradições internas e internacionais.

Atenta-se, inclusive, ao surgimento da subjetividade jurídica como a busca de uma das primeiras formas de determinação da pessoa, enfatizando o aspecto ideológico deste processo:

O primeiro desdobramento do sujeito de direito, isto é, a primeira forma que Hegel, no desenvolvimento da Filosofia do Direito, faz derivar do sujeito do direito, é a propriedade. A propriedade aparece, então, como a primeira determinação da pessoa: capacidade jurídica que, segundo Hegel, está contida na personalidade jurídica, apresenta-se logo como a capacidade de ser proprietário (KASHIURA JÚNIOR, 2012, p. 64).

Hegel vai além, enfatizando a valoração da liberdade e da condição de proprietário que se atrela à figura do sujeito:

Noutros termos, o comportamento da vontade livre é um comportamento de proprietário e é em nome de tal comportamento que Hegel pode afirmar que não há coisa-em-si. Isto significa também que o "mistério" da coisa em si é resolvido [...] pelo direito de propriedade! [...] Em última instância, a coisa-em-si não é, aqui mesmo, senão a expressão de uma propriedade imóvel, entravada, fixada por relações de produção arcaicas. Hegel, num só golpe, põe o dedo 
na questão: se o sujeito produz a propriedade privada - e, ao mesmo tempo, é produzido por ela -, então não há coisa-em-si, não há senão atividade de um sujeito proprietário (ELDEMAN, 1973, p. 76).

O próprio Hans Kelsen, apontado como referência do positivismo jurídico, reconhece aspectos ideológicos atrelados à propriedade privada fora do âmbito do aspecto normativo e positivista:

A função ideológica desta conceituação do sujeito jurídico como portador (suporte) do direito subjetivo, completamente contraditória em si mesma, é fácil de penetrar: serve para manter a ideia de que a existência do sujeito jurídico como portador do direito subjetivo, quer dizer, da propriedade privada, [...]. (KELSEN, 1999, p. 120)

Para que o movimento valor alcance o seu apogeu, foi preciso a inserção na ideia de contrato, de modo que dentro da ideia de contrato as formulações do sujeito de direito e da propriedade tornaram-se evidentes:

No contrato, o movimento valor alcança o seu auge. Os avanços anteriormente acumulados na formulação do sujeito de direito e da propriedade tornam-se evidentes. O desdobramento, na análise do contrato, da ideia do direito como determinação do sujeito conduz Hegel a uma sintonia plena com uma cadeia infinita de relações jurídicas constituída pela economia capitalista - sintonia que, não por acaso, aparece sobretudo ao longo do desenvolvimento do contrato de troca, no qual Hegel consegue captar nucleares da circulação de mercadoria (KASHIURA, 2012, p. 76).

De fato, grandes contribuições são desenvolvidas na apresentação de um sujeito de direito dentro do pensamento de Hegel:

O sujeito de direito se encontra, ao longo da Filosofia do direito, com todos os seus atributos fundamentais - a abstração da pessoa, núcleo da vontade livre, capaz de propriedade essencialmente plena, alçado a proprietário de si mesmo como coisa - e, mais ainda, se encontra, desde que “a cortina se abre” numa condição necessariamente universal (KASHIURA, 2012, p. 109).

Assim, uma vez admitido um processo multifatorial decorrente de uma série de influências, o momento de formalização de direitos (critério positivista) acaba reduzido a apenas uma das várias influências fenomênicas, levando a proposta a revisar o que seria o critério juspositivista, ou seja, o momento histórico e político em que prerrogativas são positivadas e formalizadas.

Busca-se, assim, para a respectiva pretensão, a investigação em uma das obras que mais projetaram o pensamento das gerações ou dimensões de direitos, correspondente a A Era dos Direitos, na qual, em pontual recorte, o autor, Norberto Bobbio, assume a divergência com Karl Marx no trabalho Sobre a questão judaica, no qual o autor irá analisar um dos mais relevantes documentos pertencentes à primeira fase geracional de Karel Vasak: 
[...] De nenhum modo se tratava do homem abstrato, universal! O homem de que falava a declaração era, na verdade, o burguês; os direitos tutelados pela Declaração eram os direitos do burguês, do homem (explicava Marx) egoísta, do homem separado dos outros homens e da comunidade, do homem enquanto "mônada isolada e fechada em si mesma” [...] A acusação feita por Marx à Declaração era a de ser inspirada numa concepção individualista da sociedade. A acusação era justíssima. (BOBBIO, 2004, p. 46)

Desse modo, conclui-se que enquanto Norberto Bobbio reafirmava o pensamento de Vasak acerca da universalidade dos direitos, Marx afirmou que o documento não referenciava o homem universal, mas o homem burguês, fazendo uma alusão ao campo da real efetividade do momento de êxito burguês em que direitos abstratamente universais foram protegidos.

Reitera-se que o critério juspositivista de proteção e positivação de direitos, ainda que abstratamente universal, somente era efetivo para alguns - justamente, aqueles que lograram o respectivo êxito no momento histórico político em que direitos foram protegidos -, em detrimento dos demais:

A crítica oposta - segundo a qual a Declaração, em vez de ser demasiadamente abstrata, era tão concreta e historicamente determinada que, na verdade, não era a defesa do homem em geral, que teria existido sem que o autor das Noites de São Petersburgo o soubesse, mas do burguês, que existia em carne e osso e lutava pela própria emancipação de classe contra a aristocracia, sem se preocupar muito com os direitos do que seria chamado de Quarto Estado - foi feita pelo jovem Marx no artigo sobre A questão judaica, suficientemente conhecido para que não seja preciso nos ocuparmos de novo dele, e repetida depois, ritualmente, por diversas gerações de marxistas. (BOBBIO, 2004, p. 46, grifo do autor)

O pensamento de Vasak e Bobbio acaba se reduzindo a mera análise juspositivista que fica adstrita ao conteúdo, afirmando uma universalidade que não transcende ao âmbito das textualizações e positivações de direitos (análise formal e objetiva). Enquanto Marx, porém, reporta a deformidade de uma efetividade excludente que somente se materializa para alguns (certas categorias de sujeitos) em detrimento dos demais (análise material e subjetiva), reduzindo a universalidade à mera abstração.

Assim, enquanto as dimensões e gerações de direitos, na linha de pensamento de Karel Vasak, colocam o momento de positivação e formalização de prerrogativas como fatores únicos e absolutos no processo de surgimento de prerrogativas, o filósofo alemão faz uma análise subjetiva, concentrando-se em quem foram os favorecidos e beneficiados no campo da real efetividade quando direitos abstratamente universais galgaram a respectiva positivação. Trata-se, assim, de uma efetividade real excludente que sujeitou os demais à satisfação de alguns. Desse modo, a proposta aponta o momento de positivação de direitos (critério juspositivista) não mais como fator determinante no processo de surgimento de direitos, mas sim como uma das várias influências que fogem ao âmbito juspositivista e técnico normativo e que merecem consideração como influências concomitantes neste processo de determinação. 


\section{CONSIDERAÇÕES FINAIS}

A proposta expõe um dos ideários mais bem divulgados acerca da temática dos direitos fundamentais, repercutido por inúmeros fatores, entre os quais, a projeção da obra A era dos direitos, e o reconhecimento acadêmico do seu autor, Norberto Bobbio, e também pela divulgação da aula magna inaugural em uma importante instituição de direitos humanos em Estrasburgo, pelo jurista tcheco, naturalizado na França, Karel Vasak. E, ainda, pela influência pós-positivista da constitucionalização dos diversos ramos do direito que irradiam para as diversas áreas jurídicas, entre as quais, direito civil, direito penal, direito empresarial e direito tributário.

Destaca-se ainda o pensamento de Thomas Humphrey Marshall, que, com significativo reconhecimento, formulou a determinação de direitos fundamentais a partir da noção de cidadania, correspondente à associação de status enquanto associado ao direito de aquisição de direitos, desenvolvido para pensar os direitos e obrigações inerentes à condição de cidadão, havendo paralelo com as ideias de Karel Vasak.

Para Marshall, os direitos civis e políticos, determinados nos séculos XVIII e XIX, correspondem aos direitos compreendidos por Vasak como de primeira dimensão, e, por fim, direitos sociais, concluídos por Marshall no século XX, correspondem aos direitos compreendidos como de segunda dimensão por Karel Vasak.

Porém, o pensamento de Marshall possui significativos problemas em confiar, sobremaneira, nas forças do progresso e no desenvolvimento da sociedade, apesar de reconhecer que o sistema econômico funciona produzindo desigualdades. Assim, ressalta-se que Marshall foi o primeiro a elaborar a distinção sociológica entre cidadania civil, política e social, e, ao mesmo tempo, defendeu a interdependência entre esses três tipos de cidadania (MARSHALL, 1967, p. 78-79), com significativas proximidades com a característica da inter-relacionariedade dos direitos fundamentais que confronta diretamente a proposta teórica de Karel Vasak.

Outra significativa crise do pensamento de Marshall está na conformação de um pensamento que se voltou estritamente ao contexto britânico, sendo uma análise com significativas restrições quanto às peculiaridades inglesas inviabilizadoras de uma fórmula universal para o processo de determinação de direitos, sem descartar a ausência expressa da menção dos aclamados direitos de quarta e quinta dimensão (direitos atinentes à solidariedade que transcende à esfera do individual), orientando para que o trabalho prossiga na proposta de Karel Vasak que abarca não só as prerrogativas da tutela coletiva, mas a universalização de outros países. 
A confirmação dos vícios por vertentes críticas, a começar pelos internacionalistas, que observaram que, do ponto de vista dos tratados e convenções internacionais, as primeiras proteções de direitos atinentes à pessoa humana alcançaram direitos relativos ao trabalho, com a Convenção da OIT de 1919, e não direitos civis e políticos, como pretendia a proposta das gerações elaborada por Karel Vasak.

O problema de se verificar o surgimento e conformação de prerrogativas a partir do critério de positivação de direitos aparece quando se confere o momento de proteção jurídica para os mesmos direitos, em documentos de natureza diversa das textualizações de ordem constitucional. Conclui-se, assim, a partir da averiguação dos tratados e convenções internacionais, que a proteção ocorreu primeiramente em relação aos direitos atinentes ao trabalho, com a mencionada convenção da OIT, e não quanto aos direitos civis, como pretendeu a proposta de Karel Vasak.

O trabalho, na perspectiva do conteúdo (critério objetivo), conclui que o ideário das dimensões de direitos conflita diretamente com características básicas dos direitos fundamentais, entre as quais, a indivisibilidade ou ainda a inter-relacionariedade, de modo a reduzir as dimensões de direitos às crises na própria perspectiva dos conteúdos e dos direitos que foram juridicamente protegidos.

O equívoco, ou vício do pensamento, inaugurado por Vasak está no critério sobre o qual o seu pensamento se assentou, inclusive como herança do positivismo hermético, na forma de pensar como os direitos surgiram e foram determinados até os dias atuais. Ou seja, a proposta de Vasak coloca o momento de previsão ou positivação jurídica como único e exclusivo critério determinador dos direitos fundamentais, e não como uma entre as várias influências a serem consideradas no processo de surgimento e determinação de prerrogativas.

Há que ser considerado que a proteção jurídica e o processo de positivação podem, sim, influenciar o respectivo processo de surgimento e determinação dos direitos, porém, não na qualidade de única e absoluta fonte (critério) a ser considerada, devendo ser vislumbrados em conjunto com todas as demais influências na análise e na verificação de surgimento de direitos fundamentais.

Quando o critério de positivação ou proteção jurídica deixa de ser a única e absoluta fonte de determinação dos direitos, passando a ser vislumbrado apenas como influência no processo de conformação dessas prerrogativas, as redefinições do real significado das proteções e positivações de direitos, dentro do processo de surgimento de prerrogativas, passam a ser questionadas.

Deve-se compreender que a positivação jurídica não é o critério absoluto para determinação dos direitos e está reduzida a mera influência; vale salientar que certos direitos que, muitas vezes, são 
considerados como inerentes desde sempre à pessoa humana, só tiveram sua proteção e positivação jurídica em um ponto na linha do tempo de todo o histórico humano, e justamente por dependerem do êxito político de categorias de sujeitos que positivaram direitos abstratamente universais para serem efetivos apenas para si, excluindo da efetividade os demais.

Portanto, na perspectiva dos direitos juridicamente protegidos, o pensamento de Karel Vasak confronta características peculiares dos direitos compreendidos como fundamentais, entre os quais, a inter-relacionariedade (afastando a independência que as dimensões pressupõem entre si, uma vez que os direitos de uma estão interligados com os das outras) e a indivisibilidade.

A solução juspositivista apontada baseia-se na crise dos pensamentos que apontam um processo de determinação dos direitos compreendidos como fundamentais, e se encontra em doutrinas majoritariamente internacionalistas, destacando-se o trabalho Classificação dos direitos fundamentais: do sistema geracional ao sistema unitário, de Jairo Schäfer.

Assim, desconsidera-se a fragmentação dos conteúdos das dimensões de direitos que foram propostos em fases estanques e autônomas de proteção, em que pese se tratar de prerrogativas indivisíveis e incindíveis, de aplicabilidade imediata por meio da técnica jurídica pós-positivista intitulada ponderação de interesse, que enfatiza o aspecto de princípios desses direitos para a respectiva aplicação, desconsiderando integralmente as propostas fragmentárias de direitos de Thomas Humphrey Marshall e de Karel Vasak.

Ocorre que, em que pese a temática juspositivista bastante atual, esta acaba reduzida à abstração, ao considerar o surgimento e a determinação dos direitos sem o suficiente vislumbre das oscilações históricas de diferentes nações e localidades, bem como da natureza das fontes jurídicas de proteção diversas que não conseguem diagnosticar as respectivas contradições jurídicas.

Em suma, as correntes juspositivistas que se identificam entre o direito e a técnica normativa, ainda que sejam discussões contemporâneas e, por invocarem o pós-positivismo, atuais, acabam redundando no tecnicismo de princípios e valores humanistas que renovam e somente reiteram o arcabouço juspositivista que não considera outros fatores na produção de direitos. Conclui-se, assim, na presente proposta, que há outros fatores, além do juspositivismo e do tecnicismo normativo, que restringem e reduzem a compreensão e o enriquecimento das ideias atinentes ao juspositivismo.

Por isso, a afirmação crítica aos critérios juspositivistas que levam o trabalho ao desenvolvimento de duas questões principais - a primeira, afirmando outras influências e fatores de naturezas diversas muito além do critério juspositivista como único e exclusivo a ser considerado no processo de determinação dos direitos (influências de ordem sociológicas, antropológicas, 
tecnológicas, psicológicas, históricas, políticas, muito além das jurídicas e positivas), e, por fim, a extensão que tenta rever e redefinir o critério juspositivista no processo de determinação de direitos.

Nesse intento de redefinição da verificação do momento em que direitos foram historicamente normatizados e reconhecidos (critério positivista), o trabalho reporta a obra que mais divulgou e projetou o pensamento de Vasak, correspondente a A era dos direitos, de Norberto Bobbio, que assumiu uma pontual divergência em relação a Karl Marx quando este afirma, em Sobre a questão judaica, que um dos documentos mais relevantes da proposta das dimensões dos direitos não referenciava o homem universal, mas o homem burguês.

Percebe-se, assim, na divergência assumida por Bobbio em detrimento a Marx, os problemas de abstração jurídica do positivismo que não transcende e não supera o âmbito das respectivas previsões e textualizações, restringindo a universalidade desses direitos à mera abstração do dever ser.

As positivações de direitos possuem uma universalidade meramente abstrata, pois não transcendem à esfera das textualizações e acabam sendo efetivas somente para alguns, em detrimento dos demais, havendo uma positivação de direitos que, embora abstratamente universais, são efetivos somente para determinadas categorias que lograram êxito no momento histórico em que galgaram a proteção e respectiva positivação.

Portanto, os critérios juspositivistas acabam reduzidos somente a um dos fatores a serem considerados no processo de afirmação de prerrogativas, e não em um fator único e determinante, devendo ser analisados juntamente com outros (sociológicos, políticos, antropológicos, etc.)

Ainda, com o objetivo de redefinir o critério juspositivista na afirmação de direitos, vale uma análise que realce os reais interesses políticos que coadunaram com a proteção e formalização dos direitos. Ou seja, vislumbrando os reais beneficiados, favorecidos e interessados na normatização de prerrogativas, percebe-se como válida a extensão deste trabalho em uma evolução terminológica que se coadune com o afastamento ideológico dessas perspectivas juspositivistas que evoluíram o momento de positivação de direitos de “gerações” para “dimensões” e, neste trabalho, a proposta está em reduzir a mera influência a ser verificada no conjunto de fatores que determinam tais direitos.

O critério juspositivista da normatização de direitos não é, portanto, o fator determinante neste processo, mas sim um dos fatores a serem considerados no processo de afirmação de direitos, devendo ser analisado juntamente com fatores que ajudem a identificar os reais interessados e favorecidos com o respectivo reconhecimento, admitindo-se, assim, categorias que estariam se sujeitando a essas proteções. 
Reitera-se que as ideias de gerações ou dimensões elevaram os critérios juspositivistas ao fator absoluto e exclusivo no processo de surgimento de direitos; porém, o presente trabalho reduziu esses mesmos critérios a apenas um entre os vários fatores, ou seja, trata-se de mera influência a ser estudada conjuntamente com outras e, por isso, convém reduzir o momento de positivação de prerrogativas, não mais como único e exclusivo fator determinante no surgimento de direitos, mas sim como uma das várias influências a serem analisadas no conjunto multifatorial de surgimento de direitos.

\section{REFERÊNCIAS}

AGAMBEN, Giorgio. Stato di eccezione. Torino: Bollati Boringhieri, 2003.

BARROS, Sergio Rezende. Noções sobre Gerações de Direitos. [20--]. Disponível em: <https://goo.gl/zD7HH4>. Acesso em: 26 out. 2015.

BOBBIO, Norberto. A era dos direitos. Tradução Carlos Nelson Coutinho. Rio de Janeiro: Campus, 2004.

BONAVIDES, Paulo. Curso de Direito Constitucional. 19. ed. São Paulo: Editora Malheiros, 2006.

BRASIL. Supremo Tribunal Federal. Recurso Extradordinário n ${ }^{\circ}$ 633703. Relatoria de Gilmar Mendes, julgamento em 23/3/2011. Disponível em: <www.stf.jus.br>. Acesso em: 27 out. 2015.

CANÇADO TRINDADE, Antônio Augusto. A interação entre direito internacional e o direito interno na proteção dos direitos humanos. Arquivos do Ministério da Justiça, n. 182, jul./dez. 1993. p. 2754.

CARVALHO, José Murilo. Cidadania no Brasil: o longo caminho. Rio de Janeiro: Civilização Brasileira, 2001.

EDELMAN, Bernard. Le sujet du droit chez Hegel. La Pensée, n. 170, 1973. p. 70-85.

FALCON Y TELLA, Fernando. Challenges for Human Rights (Nijhoff Law Specials). Boston: Martinus Nijhoff Publishers, 2007.

GIDDENS, Anthony. Structuralism, post-structuralism, and the production of culture. Stanford: Stanford University Press, 1987.

HONESKO, Raquel Schlommer. Discussão histórico-jurídica sobre as gerações de direitos fundamentais: a paz como direito fundamental de quinta geração. In: FACHIN, Zulmar. Direitos fundamentais e cidadania (Org.). São Paulo: Método, 2008. 
KASHIURA JÚNIOR, Celso Naoto. Sujeito de direito e capitalismo. 2012. 177 f. Tese (Doutorado em Filosofia e Teoria Geral do Direito) - Faculdade de Direito da Universidade de São Paulo, São Paulo, 2012.

KELSEN, H. Teoria pura do direito. Tradução João Baptista Machado. 6. ed. São Paulo: Martins Fontes, 1999.

MARMELSTEIN, George. Curso de direitos fundamentais. São Paulo: Atlas, 2008.

MARSHALL, Thomas Humphrey. Cidadania e classe social. Rio de Janeiro: Zahar Editores, 1967.

MASCARO, Alysson Leandro. Crítica da legalidade e do direito brasileiro. São Paulo: Quartier Latin, 2008.

MAZZUOLLI, Valério Oliveira. Curso de direito internacional público. São Paulo: Revistas dos Tribunais, 2013.

MOURA, Aline Beltrame. O Discurso da cidadania em Marshall: a influência do modelo clássico na teoria jurídica moderna. Revista Jurivox v. 10. Patos de Minas: 2009, p. 22-34.

PIOVESAN, Flavia. A Constituição Brasileira de 1988 e os tratados internacionais de proteção aos direitos humanos. In: PIOVESAN, Flavia (Org.). Temas de direitos humanos. 2. ed. São Paulo: Max Limonad, 2003.

SARLET, Ingo. A eficácia dos direitos fundamentais. 9. ed. Porto Alegre: Livraria do Advogado, 2008.

SCHÄFER, Jairo. Classificação dos direitos fundamentais: do sistema geracional ao sistema unitário: uma proposta de compreensão. 2. ed. Porto Alegre: Livraria do Advogado, 2013.

WEIS, Carlos. Direito Humanos Contemporâneos. 1. ed. São Paulo: Malheiros, 1999.

WEIS, Carlos. Direitos Humanos Contemporâneo. 2. ed. São Paulo: Malheiros, 2010.

Norton Maldonado Dias Mestre em Direito pelo Centro Universitário Eurípides Soares da Rocha - Marília. Professor da Faculdade de Direito de Sinop (Fasipe, Sinop, MT, Brasil). Advogado. E-mail: maldonadodias@hotmail.com.br

Edinilson Donisete Machado Doutor em Direito pela Pontifícia Universidade Católica de São Paulo (2006). Mestre em Direito pela Universidade Estadual Paulista Júlio de Mesquita Filho (2000). Professor titular do Centro Universitário Eurípides Soares da Rocha - Marília (Univem, Marília, SP, Brasil) e da Universidade Estadual do Norte do Paraná. E-mail: ednilson@univem.edu.br

Este artigo científico foi orientado pelo professor Edinilson Donisete Machado e decorreu da dissertação de mestrado intitulada Da Crise das Dimensões de Direitos em face aos Sujeitos e aos Conteúdos Juridicamente Protegidos, de autoria de Norton Maldonado Dias, arquivada no Centro Eurípides de Soares da Rocha (2015). 